\title{
МЕДИЦИНСКАЯ АНТРОПОЛОГИЯ
}

УДК $39+316.347+316: 61$

DOI: $10.33876 / 2311-0546 / 2022-1 / 174-192$

(C) Н.А. Вяткина

\section{ИЗМЕНЕНИЕ ОТНОШЕНИЯ ПАЦИЕНТОВ К ЗДРАВООХРАНЕНИЮ, КАК РЕЗУЛЬТАТ ПАНДЕМИИ СОVID-19 В РОССИИ}

Взаимоотношения врача и паџиента в истории современной России постоянно претерпевают изменения. Пандемия COVID-19, которая уже два года оказывает влияние на планету, преобразила самые разные сферы деятельности человека: экономику, политику, транспорт, сочиальную жизнь, торговлю, туризм и многое другое. Но больше всего пандемия, безусловно, отразилась на здравоохранении. За новостями о количестве заболевших, умериих, привитых следит весь мир. Медицина повсеместно стала главной темой обсуждения. $A$ в фокусе внимания медицинских антропологов оказались люди, так или иначе столкнувшиеся с новой коронавирусной инфекцией. Благодаря развитию интернета мы получаем многочисленнье свидетельства пачиентов, ведущих в сочииальных сетях хронику своего пребывания в лечебных учреждениях, читаем об их опыте вызова врачей на дом, анализируем полученную информачию о заболевании, лечении, правилах и требованиях изолящии или ПЦР-тестирования. Врачи стали главныли героями сегодняшнего дня. И если из года в год опросы показывали, что престиж и уважение врачебной профессии снижаются, то на фоне пандемии COVID-19 наметились некоторые изменения. $B$ данной статье представлень результаты сравнительного анализа высказываний пациентов о состоянии современной российской медиџины за год до и во время пандемии. Пациенть стали активнее хвалить врачей и с бо́льшим уважением отзываться об их труде. Среди негативных отзывов все больше появляется личных историй об успешно проведенном лечении или положительном взаимодействии с системой здравоохранения.

Ключевые слова: отношения врача и паџчента, пандемия COVID-19, медицинская антропология, российское здравоохранение

Ссылка при цитировании: Вяткина Н.A. Изменение отношения пациентов к здравоохранению, как результат пандемии covid-19 в России // Вестник антропологии, 2022. № 1. С. 174-192.

Вяткина Наталья Александровна - аспирант Центра медицинской антропологии, Институт этнологии и антропологии им. Н.Н. Миклухо-Маклая РАН (Москва, Ленинский пр. 32-А). Эл. почта: natalia.vyatkina@gmail.com ORCID https://orcid.org/0000-0002-1288-5219 


\section{THE CHANGING ATTITUDE OF PATIENTS TO HEALTHCARE AS A RESULT OF THE COVID-19 PANDEMIC IN RUSSIA}

The relationship between a physician and a patient in the history of modern Russia has constantly been changing. The COVID-19 pandemic, which has been affecting the planet for two years, modified many areas such as the economy, politics, transport, social life, trade, tourism, and others. Most of all, the pandemic has certainly affected healthcare. Everyone in the world monitors the news about the number of sick, dead, vaccinated regularly. Medicine has become the main topic of discussion. People who somehow encountered the new coronavirus infection have become the focus of attention of medical anthropologists. Thanks to the development of the Internet, we see numerous testimonies of patients chronicling their stay in medical institutions on social networks. We can observe their experience of calling physicians analyzing the information received about the disease, treatment, rules, and requirements of isolation or PCR tests. Physicians became the main characters. Polls had been showing that the prestige and respect of the medical profession in Russia had been declining every year; nevertheless, the COVID-19 pandemic caused certain changes. This article presents the results of a comparative analysis of patients' assessments of modern Russian medicine a year before and exactly at the beginning of the pandemic. Patients have become more active in defending physicians and started showing great respect to their work. Along with the negative reviews, personal stories about successful treatment or interaction with the healthcare system became more frequent. We all hope that this trend will persist.

Keywords: doctor-patient relationship, COVID-19 pandemic, medical anthropology, Russian healthcare

For Citation: Vyatkina, N.A. 2022. The Changing Attitude of Patients to Healthcare as a Result of the COVID-19 Pandemic in Russia. Herald of Anthropology (Vestnik Antropologii) 1: 174-192.

Author info: Vyatkina, Natalia A. - postgraduate student, Institute of Ethnology and Anthropology of the Russian Academy of Sciences (32-A Leninsky Prospect, Moscow, 117334). E-mail: natalia.vyatkina@gmail.com ORCID https:/orcid. org/0000-0002-1288-5219

\section{Введение}

Взаимоотношения врача и пациента находятся под пристальным вниманием медицинской антропологии и социологии медицины уже долгое время. Эффективность коммуникаций внутри системы здравоохранения и в особенности между врачом и пациентом напрямую оказывает влияние на результативность лечения (Gordon et al. 1995; DiMatteo 1994; Stewart 1995; Williams et al. 1998). Удовлетворенность пациента на всем пути пользователя системы здравоохранения, начиная от записи на прием, 
взаимодействия с персоналом медицинской организации, сбора анамнеза, описания жалоб, прохождения клинико-диагностических процедур, постановки диагноза и полного соблюдения назначений врача приводит к лучшим исходам лечения. На каждом из этих этапов пациент вынужден взаимодействовать с различными представителями системы здравоохранения, поэтому качество этой коммуникации становится важным базовым элементом здоровьесбережения в целом (Wynia \& Matiasek 2009).

Ориентация на пациента и необходимость учета его мнения уже несколько десятилетий у медиков не вызывает сомнения. Более того, во многих странах создание пациентоориентированной медицины является приоритетной задачей, хотя эксперты до сих пор не сформировали единого мнения по поводу элементов, которые должны ее составлять (Mead \& Bower 2000). Эта медицина должна учитывать желания, предпочтения и потребности пациентов, а также своевременно реагировать на них, считают одни (Laine \& Davidoff 1996); другие же полагают, что ее различные компоненты должны в первую очередь находиться между собой во взаимосвязи (Stewart et al. 2003). В целом основными характерными особенностями пациенториентированной или пациентоцентричной медицины считаются:

1. крепкие и отлаженные взаимоотношения между врачом и пациентом, а также постоянная работа над их улучшением;

2. понимание организма пациента как единого целого, а не как набора отдельных подверженных патологии органов;

3. изучение и воздействие не только на саму болезнь, но и на опыт переживания болезни;

4. компромисс в принятии медицинских решений, полное информирование и партнерство врача и пациента;

5. внимание к профилактике и стимулированию ранних обращений;

6. оценка личных пределов возможностей и ограничений пациента (финансовые возможности, временные ресурсы, необходимые усилия и проч.).

Важность построения эффективных коммуникаций между врачом и пациентом в РФ также уже стала очевидной, доказано, что их отлаженное взаимодействие ведет к повышению удовлетворенностью медицинской помощью и снижению претензий и жалоб (Денисов 2012). Тем не менее, пока удовлетворенность россиян системой здравоохранения остается на низком уровне. При этом удовлетворенность качеством медицинской помощи, оказываемой в коммерческих медицинских организациях, значительно превышает показатели государственных - 88,5\% против 27,6\% (Кулакова и др. 2011).

\section{Методология исследования}

Высказывания пациентов в сети интернет об их опыте обращения за медицинской помощью стали сегодня ценным источником информации и исследовательским полем для антропологов во всем мире. На IX Международном интердисциплинарном научно-практическом симпозиуме «Медицинская антропология перед новыми вызовами: мир, люди, знания и культуры в эпоху пандемии», который прошел 18-20 ноября 2021 г. в Москве, на круглом столе «Врачи и пациенты: проблемы коммуникации, (не)доверия и терапевтического выбора до и в период пандемии» ${ }^{1}$ участ-

\footnotetext{
${ }^{1}$ См. материалы Симпозиума на сайте журнала «Медицинская антропология и биоэтика» http:// www.medanthro.ru, а также обзорную статью о прошедшем мероприятии (Харитонова 2021).
} 
ники дискуссии сошлись во мнении о том, что проблемы медицинского характера, раньше переживаемые приватно, сегодня, благодаря интернету вышли в публичное пространство. Пациенты охотно оповещают своих подписчиков об уровне антител, прививках, опыте переживания болезни, делятся советами о лечении, ведут дневниковые записи из ковидных госпиталей. Подобная трансляция эмоций и переживаний приводит к ответной реакции интернет-друзей и, по словам самих пользователей, оказывает большую поддержку в период лечения. Очевидно, что наблюдение за публичной активностью различных интернет-пользователей дает обширную почву для медицинских антропологов и представителей смежных отраслей знания.

Основой для данного исследования стал сравнительный анализ высказываний подписчиков канала в сети Telegram Артемия Лебедева. Блогер задал вопрос своим подписчикам «Что не так с нашей системой здравоохранения» 12 мая 2019 г. (ПМА 2019), а затем повторил свой пост в начале пандемии 16 апреля 2020 г. (ПМА 2020) У блогера очень активная и вовлеченная аудитория, в середине апреля 2020 г. количество подписчиков Telegram-канала составляло 249717 человек, сегодня эта цифра возросла до 254 809. Поскольку пользователи сети в целом являются представителями так называемого русскоязычного сегмента интернета, в комментариях было множество откликов не только о ситуации в регионах России, но и в других государствах. Бывшие соотечественники охотно делились своим опытом обращения за медицинской помощью в стране проживания, а также аргументированно сравнивали различные системы здравоохранения.

Количество комментариев пользователей к посту А. Лебедева в 2019 г. составило 234, в 2020 г. - 418. Рост комментариев почти в два раза может быть связан с увеличением числа подписчиков блогера; может быть, это произошло благодаря более широкому распространению сети Telegram. Возможно также, что на фоне пандемии, когда здоровье стало основной темой, интерес пользователей к обсуждению поднятой блогером проблемы вызвал больший отклик.

Важно отметить, что А. Лебедев никогда не стеснялся в выражениях; он активно использует обсценную лексику, что дает его подписчикам возможность высказывать свои мнения в такой же манере. Многие комментарии, которые имели только эмоциональную окраску, мной не рассматривались. При этом какие-то мнения были развернутыми, с подробным описанием личного опыта обращения за медицинской помощью для себя или своих близких. Таким образом, полагаю, если оценивать их как дискретные единицы текста, включающие в себя четкое начало и окончание (Троиук 2004), данное исследование можно считать нарративным анализом, который позволяет более подробно изучать конструкции и интерпретации пациентского опыта (Лехичиер 2012; Лехичиер 2018).

В 2019 г. мной были отобраны 119 наиболее информативных и развернутых комментариев, а в 2020 г. - 71. Мнения пользователей были разделены на негативные и позитивные, дополнительно они были сгруппированы по тематикам. Отдельно были выделены мнения представителей медицинской профессии или их родственников, как описание проблем здравоохранения изнутри.

В дополнение к проведенному анализу мной было проведено экспертное интервью с врачом (врач общей практики, 63 года) (ПМА 2021) для того, чтобы обе стороны и пациенты, и врачи могли иметь голос в данном исследовании, учитывая тот факт, что большое количество претензий было адресовано непосредственно врачам. 


\title{
Результаты исследования: доковидная ситуация
}

Негативные комментарии, которых было подавляющее большинство, распределены по проблематике и темам. На основании количества комментариев, затрагивающих конкретную, озвученную проблему, составлены взвешенные списки (см. рисунки ниже).

\section{Обвинения в некомпетентности Организация процессов Коррупция Катастрофа в регионах}

\section{Грубость и неуважение Претензии к общению/отношению}

\section{Государственное здравоохранение бесполезное}

\author{
Ошибки/халатность Претензии к инфраструктуре

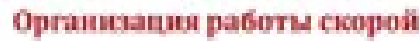

Рис. 1. 2019 год (фото автора на материалах сайта «Взвешенный список. Основной негатив»).

Pic.1. 2019 (photo by the author on the materials of the site "Weighted list. Main negative").

В 2019 г. (Рис. 1) среди основных проблем современного российского здравоохранения выделялась некомпетентность медицинского персонала различного уровня.

[Врач] выписал мне список бесполезных лекарств вместо того, чтобы не выписать ничего.

[Врач сказал] Пройдет, не переживайте... Так и ушел ни с чем... Такая медицина у нас.

Половина врачей вместо реального лечения прописывает псевдолекарства и процедуры из оккультной медицины. Уже один этот факт иллюстрирует, что с медициной, мягко говоря, не всё в порядке.

Не умеют диагностировать болезни... вообще... Соответственно лечат, не от того, что болит...

У нас к какому врачу не приди, он обязательно скажет: П**** ц! Кто это вас так лечил, кто это вам сказал?

Крайне низка квалификация специалистов. Как в государственных учреждениях, так и в частных. Хорошего специалиста нужно искать по знакомым, таких передают из рук в руки. И такой специалист все равно будет платный.

Важно отметить, что с развитием интернета и ростом количества источников о медицине у многих пользователей сети сложилось убеждение, что они знают и разбираются в вопросах, связанных со своим здоровьем и здоровьем своих близких. Врачи же считают, что медицинская грамотность их пациентов является мнимой (Вяткина 2019). Знания о здоровье могут накапливаться по мере приобретения опы- 
та конкретного заболевания, они фрагментарны и не системны, основываются на советах родственников, знакомых, друзей, ТВ-программ или бывают получены в сети интернет. Качество этой информации часто оказывается невысоким или неприменимым к конкретному случаю, но доверия вызывает больше (Пузанова, Хуртина 2014). Проблема доверия к различным государственным институтам и в целом в обществе вызывает интерес различных исследователей, в том числе экономистов и социологов $^{1}$, по мнению медицинских антропологов в России сегодня сложилась ситуация «недоверия» к системе здравоохранения и врачам (Ожиганова 2020), что позволяет проявляться подобного рода претензиям со стороны пациентов.

Большое количество негативных высказываний о проблемах в российском здравоохранении в 2019 г. относилось к общей «бесполезности» государственной бесплатной медицины.

А если я не болею, на какой ${ }^{* *}$ н я плачу за обязательное медицинское страхование? А если даже и заболею, ни в жизнь не пойду в бесплатную поликлинику, нет у меня денег так дорого лечиться.

Часто хожу в государственные поликлиники. Потому что за них я и все уже остальные заплатили. Но в этом случае вступает российский менталитет, врачи считают, что на работе им мало платят, поэтому там нету сервиса, еще они заинтересованы, чтобы мы обращались в частные поликлиники, потому что большинство врачей работают в тех же самых частных поликлиниках.

Недофинансированность системы здравоохранения и рост количества платных услуг, а также развитие рынка коммерческих медицинских организаций не привели к улучшению качества медицинских услуг в государственных лечебных учреждениях, там продолжают экономить на времени, инфраструктуре, лекарственных препаратах и перевязочных материалах. Основные принципы системы обязательного медицинского страхования «здоровый платит за больного» и «богатый платит за бедного» (Иевенко, Дубас 2010) не покрывают всех расходов системы. Это привело к разделению пациентов на тех, кто может себе позволить платить за медицинскую помощь, и тех, кто не может и вынужден обращаться в государственные медицинские организации. В регионах же обращение в платные клиники часто является единственной возможностью получения медицинской помощи в ограниченные заболеванием или условиями труда сроки.

Многие комментарии в 2019 г. были откровенно грубыми и неуважительными по отношению к врачам. Позволю себе проиллюстрировать этот тезис ярким примером:

Раздражают повсеместно встречающиеся врачи, которые пытаются лечить последствия, а на причины заболевания им на*** ть. Или просто на***ть на пациента. <..> Сделала вывод, что на любое недовольство врачом проще сразу писать жалобу. Пишешь жалобу - и о чудо, тебя и приняли сразу, и обращаются как к человеку, и даже как будто хотят вылечить. Поэтому неуважаемые врачи-пи******ы, которые любят назначать от всех болезней арбидол, идите нах ${ }^{* *}$, пожалуйста, и там жалуйтесь на свои зарплаты.

\footnotetext{
${ }^{1}$ См. решение Научно-экспертного совета при Председателе Совета Федерации Федерального Собрания Российской Федерации по итогам заседания на тему «Доверие как критический фактор достижения стратегических целей социально-экономического и политического развития государства» (подробнее: http://council.gov.ru, дата обращения: 10.12.2021).
} 
Специалисты сегодня сходятся во мнении, что престиж врачебной профессии значительно пострадал за постсоветскую историю России (Романов, Ярская-Смирнова 2013). Свою роль здесь сыграл безусловно коррупционный фактор, тиражирование в СМИ и сети интернет дел о «врачебных ошибках», а также усугубление проблем взаимоотношений и недостаточности человеческого отношения со стороны медицинского персонала в государственных медицинских организациях. Это так же является одной из причин недостаточного финансирования отрасли, когда стандартами и указами время приема было ограничено, а нагрузка повысилась.

Очереди, невозможность получить быстрое и качественное обслуживание, отвратительно некомпетентные психотерапевты, психиатры, гинекологи и эндокринологи в государственных учреждениях. Редкие врачи отслеживают новые исследования в своей и смежных областях, повышают квалификацию, главный и самый нелепый пример - ветрянку до сих пор лечат зеленкой. Дикое неуважение к пациентам, в особенности к женщинам в роддомах, в особенности - во время родов. Про коррупцию и говорить нечего :)

Недоступность квалифицированной медицинской помощи нигде, кроме МСК и СПб < .. > отношение к пациенту, как неполноценному человеку.

Халатность. <...> Врач поставил диагноз, а на вопрос «что это такое и как с этим быть» порекомендовал мне погуглить.

Задача улучшения качества взаимоотношений врачей и пациентов сегодня является насущной во многих странах мира. Эффективная коммуникация врача и пациента не только приводит к взаимной удовлетворенности, лучшим исходам лечения и соблюдению рекомендованных мер профилактики, но и приводит к экономии времени врача (Котов 2020). В нашей стране эта проблема стоит особенно остро. Колоссальный объем взаимных упреков, жалоб и требований только эскалирует ситуацию. Медицинские антропологи уже активно изучают эту проблему, а также настаивают на необходимости гуманизации медицины ${ }^{1}$ (Моисеева 2013; Харитонова 2020).

Считаю необходимым подчеркнуть, что современные пациенты - это не слепые «требовательные клиенты» (Присяжнюк 2012), и хотя случаи пациентского экстремизма уже не редкость, россияне склонны вполне адекватно оценивать ситуацию в системе здравоохранения и идентифицировать главные ее проблемы и недостатки, а также те проблемы, которые возникают по причине самих пациентов: игнорирование профилактики, необоснованные обращения в службу скорой медицинской помощи, поздние обращения, низкий уровень медицинской грамотности и проч.

Самая частая проблема в медицинских гос. учреждениях - малое количество времени, уделяемое пациенту. Иногда просто не успевают нормально анамнез собрать - время вышло и по графику уже следующего принимать надо. В частных с этим намного лучше. Но частники могут и залечить - были бы деньги. А там на каждый чих найдут лечение (даже если само пройти может).

Скорая помощь, которая обязана приезжать на каждый пук и температуру 38 у взрослого человека, которая зачастую ещё и как вытрезвитель работает. В

${ }^{1}$ См.: Проект резолюции Первого Всероссийского совещания заведующих кафедрами социально-гуманитарных дисциплин медицинских вузов и колледжей // под ред. В.И. Моисеева 2021 г. о дегуманизации современного медицинского образования (опубликовано в журнале «Биоэтика (BIOETHICS)». 2021. № 1 (27). volgmed.ru. 
то время как пациенты, которые действительно нуждаются помощи ждут помощи часами.

Население, которое идёт в больницу только когда жить уже совсем невозможно, доводя себя до хронизации или тяжелейшего состояния, а потом ещё и не придерживается терапии, потому что дорого /якобы зашлаковывает организм. Общая неграмотность населения с лечением астмы баней, ожогов маслом и так далее. Убеждения, что прививки вызывают аутизм, отравляют всех ртутью.

Несмотря на большое количество негатива в комментариях пользователей Telegram-канала А. Лебедева в 2019 г., были там и положительные отзывы. Пациенты, описывая свой опыт обращения в государственные медицинские организации отмечали, что получали помощь, в том числе высокотехнологичную, в полном объеме, а изношенность инфраструктуры и необходимость ожидания - это вынужденные побочные эффекты недостаточного финансирования отрасли.

Была приятная палата и даже питание сносное. И врачи молодые и очень талантливые, которые быстро и уверенно поставили меня на ноги, не требуя ни копейки.

В моем случае все отлично с нашей медициной. Когда отказали почки 8 лет провёл на диализе, потом пересадили почку. Уже третий год пошел. Естественно, все бесплатно. Ростов-на-Дону.

Всегда лечился только в бесплатных клиниках... Все мои пломбы поставлены в обычной стоматологии бюджетной... Два раза пытался лечить в платной, но после второй выпавшей пломбы, поставленной за 2000 рублей, плюнул на это дело и спокойно лечусь в бесплатной... Неврология? Бесплатно. Полное обследование бесплатно... Не хочу как в Америке, где мне после скорой выставили бы счет на 2-3 миллиона...

Хожу к врачам только платно, так как это удобно, рядом с домом, не надо ждать миллион лет приема. Анализы все тоже платно сдаю. 2 раза недавно лежала бесплатно в больнице, все устроило, врачи умные, заботливые, во второй больнице каждый утренний обход долго рассказывали, что со мной происходит, пока у меня не оставалось вопросов. Прикинь! Радует, что цены на платную медицину доступные. Мне пришлось делать операцию платно (потому что в моей больнице отказались её делать лапароскопически), и я заплатила 45000 руб. за операцию, недельный стационар и наркоз хороший.

По-моему, с медициной все прекрасно. Врачи в большинстве умнички. Только надо понять, что процесс лечения был у нас всегда творчеством... Теперь это превращают в услугу и пытаются стандартизировать. Собственно пациенты не против и активно включились в эту тему. Что дальше? Покажет время ...

\section{Результаты исследования: эффект пандемии}

Аналогичный пост, опубликованный А. Лебедевым в 2020 г., также вызвал бурное обсуждение. Негативные комментарии остались, но общее распределение по темам во взвешенном списке изменилось (см. рис.2). 


\section{Врачи хорошие, чиновники/условия плохие Обвинения в некомпетентности Государственное здравоохранение бесполезное} Организация процессов Катастрофа в регионах

Сравнение с другими странами Претензии к общенио/отиошению

\section{Халатность Коррущщия}

Puc. 2. 2020 год

(фото автора на материалах сайта «Взвешенный список. Основной негатив»).

Pic. 2. 2020 year

(photo by the author on the materials of the site "Weighted list. Main negative").

B разгар пандемии COVID-19 и локдауна во всем мире произошла героизация работы медиков. Мировые СМИ и публичные персоны обращались к общественности, призывая заботиться о себе и окружающих, чтобы снять колоссальную нагрузку на врачей в красной зоне. Фотографии врачей после тяжелейших смен, следы от респираторов на лицах, тяжелейшее состояние врачей и медицинского персонала, а также невозможность встретиться со своими близкими затронули сердца людей по всему миру. В нашей стране фокус обвинительной риторики при описании проблем российского здравоохранения сместился с врачей на систему и чиновников. В своих комментариях к посту А. Лебедева многие выражали активную поддержку врачам, рассказывая о случаях успешного обращения за медицинской помощью. Пользователи отмечали безвыходность ситуации врачей и медицинского персонала, вынужденных подчиняться системе и соглашаться с «правилами игры» (ПМА 2020).

Есть отдельные хорошие врачи. Но система в целом не работает - ибо у руля чиновники, для которых люди - это безликие цифры статистики. И самое главное - отсутствие персональной ответственности за свои бездарные действия или бездействие.

И диагнозы ставят только те, которые «разрешено». Так что лечить могут не от того, что нужно. Мне пару раз на ушко врач говорил диагноз, но в карте писал другой...»нельзя», «запрещено»...

Уровень нагрузок, а не ответственности, у врачей увеличился, причем в разы. А нагрузки увеличивают чиновники и депутаты (законы, указы, приказы), хотят быть хорошими и д**** ть врачей. Откуда очереди? Да м**ть количество больных значительно больше, чем количество врачей, не понятно? В Европе очередь к специалисту до полугода, и никто не возмущается. И вопросы задавайте не врачам (что происходит), а власти.

По сравнению с 2019 г., в 2020 г. обвинения в некомпетентности хотя и сохранились, но их стало значительно меньше, при этом большее количество комментариев касалось необходимости поиска «своего врача», отношения с которым необходимо поддерживать и ценить, чтобы в любой ситуации, связанной со своим здоровьем или здоровьем близких, иметь возможность проконсультироваться лично, по телефону 
или с использованием мессенджеров. Также появились комментарии о необходимости повышения уровня личной ответственности за собственное здоровье.

Если бы я действительно покупала всю ту гомеопатию, которую мне выписывали, у меня бы уже сейчас был запас сахара до конца жизни (а мне 23).

Российская медицина - это как лотерея. Попадешь к толковому специалисту - разберешься с проблемой, попадешь к не очень - пиши пропало.

Ищи ВРАЧА в каждой области. Если наобум, кирдык. Поэтому: «Самые лучшие доктора в мире - доктор Диета, доктор Покой и доктор Веселье». Джонатан Свифт.

Если чисто с точки зрения профессионального мастерства врачей, пока Бог миловал, и все было хорошо, тьфу, тьфу, тьфу. Но улучшать есть что, и в плане ремонта, и питания и очередей на операции, МРТ и т.д. Но вообще страшно читать комментарии, а за здоровьем нужно следить смолоду.

Сохранились комментарии, указывающие на общую бессмысленность существования государственной системы здравоохранения и ее бесполезность. Комментаторы охотно описывали плохую организацию процессов внутри медицинских организаций, а также жаловались на ситуацию в регионах. В меньшем объеме, по сравнению с 2019 г. и в менее грубой форме, но претензии к отношению врачей и медперсонала к пациентам сохранились, как и истории о коррупции и халатности.

Сама поступила в больницу неделю назад, где помимо условий проживания, самое бл $* * * * * *$ ое - отношение врачей к пациенту, а главное лечение, которое фактически отсутствует. Люди поступают с разными диагнозами, при этом пичкают всех одними и теми же таблетками. Обследований не проводят, $\mathrm{x}^{* *}$ кладут на противопоказания к антибиотикам. Бесплатная медицина, тем более Российская- го* но полное, как в принципе и все наше правительство. Отношение ужасное, условия аналогичные!

На самом деле, просто везде наши люди и халтурка :) Но. Бесплатно тебя вылечат. Может, кое-как, но долечат. Ибо, если не долечат, им ещё и отвечать за эту бесплатную халтуру.

В системе полнейший дисбаланс. Врачи отфутболивают пациентов от одного к другому. Сдохнешь быстрее, чем пройдешь круги бюрократического ада. Система заточена на лечение симптомов, но не на лечение причины, и, если проблема хроническая, такое лечение больше вредит чем помогает. Все вышеперечисленное я прочувствовал на собственной шкуре, борясь за здоровье и жизнь своей мамы уже больше двух лет.

Совершенно неожиданным, что также отмечалось участниками круглого стола «Врачи и пациенты: проблемы коммуникации, (не)доверия и терапевтического выбора до и в период пандемии» на IX Международном интердисциплинарном научно-практическом симпозиуме «Медицинская антропология перед новыми вызовами: мир, люди, знания и культуры в эпоху пандемии», стало появление на фоне пандемии большого количества сравнений систем здравоохранения различных стран. 
Многие пользователи сети интернет либо имели опыт обращения за медицинской помощью во время поездок за рубеж до пандемии, либо эмигрировали или какое-то время проживали за границей, либо общаются с эмигрировавшими родственниками или друзьями, поэтому могут аргументированно проводить сравнения зачастую не в пользу западных систем и с точки зрения оплаты лечения личными средствами, и с точки зрения времени ожидания.

В США у меня знакомая (американка) не обращалась к врачам годами из-за постоянных болей в ноге, так как денег не было... Яростно плюсую, замучили так с х****й этой. У меня родственник в Швеции с инсультом 3 часа в приёмнике ждал. Причём скорую дорого было вызывать, попросил знакомого довезти. В России есть «золотой час» для скорых, чтоб успеть доставить по б***дь вызову на дом).

Когда вы, черти, поживете в других странах и познаете медицину, вы ох***е насколько наши врачи профессиональные. Вы кроме Российской медицины не видели никакой. Хотите получить рекомендации фельдшера за цену иномарки? Обратитесь к врачу в США. Хотите не получить лечения за 100-200 тысяч и даже диагноза? Лечитесь в Китае. Я только нашим врачам доверяю, причём бесплатным, и это учитывая, что у меня ДМС есть...

Вот кстати согласен. В какой стране вас лечили лучше, если тут плохо вас лечат, с чем вы сравниваете?

1) Экстренно попала в больницу в Амстердаме, сделали полостную операцию (гинекология), страховки не было. Боялась, что суммы будут нереальные - в итоге 2,5 тысячи евро (в Москве операция стоила бы столько же). Больница крутая, врачи вежливые, подробно все объясняли, отходила от операции недолго - выписали через сутки, встала и пошла домой. 2) В Москве скорая приезжает минут через 10. Зимой снова экстренно попала в больницу с той же проблемой, что и в Амстердаме, сделали операцию по ОМС. Врачи отличные, больница хорошая, еда иногда нормальная, иногда кошмар. Отношение к личному пространству больных идёт $\mathrm{H}^{* * *}$ й - пару раз приходилось раздеваться догола чуть ли не посреди коридора/посреди палаты с 5 другими пациентами. В целом п***й, но в Амстердаме эта проблема решалась шторкой вокруг каждой кровати. Отходила [после операции в РФ] почему-то дней 5 с болями, и швы больше. Считаю, все проблемы от отсутствия финансирования + в регионах много коррупции + совковая система субординации, а врачи у нас топ!

Защита врачей в 2020 году в целом вышла на первый план.

Сплошные вы***ы против врачей. Скамейка, м**ть, металлическая не нравится. Врач ее туда поставил? Ты как профинансировал ОМС, так и получил. Полечись за рубежом, об******ся от тарифов. Врач оказывает медицинскую помощь, а не услугу. Не нравится, лечись подорожником.

Хз, как оно. Читаю комментарии - везде все плохо, врачи убийцы. Как пойду сам лечиться - ну в очереди потуплю в телефон, с регистратурой общаюсь вежливо, отвечают так же, врачи болячки лечат, жаловаться не на что. Непонятно, в общем. 
В Москве - проблемы реформации и уничтожение младшего медперсонала. Врач московской поликлиники (который, на минуточку, лет 10 учился) $80 \%$ времени занимается чем угодно, кроме своих прямых обязанностей. В основном ждёт, пока ЕМИАС отвиснет, и заполняет разнообразную отчётность. В порядке вещей считается посадить врача обзванивать пациентов или заставить сгонять за бумажками. По отношению к пациентам практикуется вредный подход «лишь бы не было жалоб», что выливается в удовлетворение абсолютно всех хотелок самых неадекватных и скандальных независимо от эффективности терапии, которую они сами себе придумали.

Мне кажется $\mathrm{x}^{* * *}$ о только с заработной платой медработников. Наверное, за такие деньги лечить не хотца, только убивать...

У меня вот только положительный опыт. Пришел в обычную поликлинику с жалобами, после первого же осмотра отправили на МРТ (несколько дней подождал), потом больница. После всех необходимых анализов (один пришлось сделать за свой счет, он не входит в ОМС) поставили диагноз. Через две недели после больницы уже начали выдавать бесплатное лекарство, которое мне помогает, если перестанет - есть более сильные варианты. С бабками, очередями и хабалками можно и смириться, учитывая, что это бесплатная клиника.

Даааа... люди, вы даже не представляете, какая нагрузка на врачей сейчас, вас элементарно скоро некому лечить будет... Старое поколение выходит на пенсию, а новое просто не идет из-за низких заработных плат, высокой ответственности и отношения людей! Да-да, вы не ослышались, не только у вас претензии к врачам, но и у них к вам! Думаю, тут половина комментаторов в полном объеме не платит налоги, сидит на черных зарплатах, или вовсе не работает! Наверное, действительно лучше будет платная медицина для вас... Я не врач, врач моя мама, и весь коллектив её сменился (она работает в областной больнице), кто-то ушел в частные клиники, лечить людей по ДМС, кто-то ушел на пенсию... Лучше уволиться, нах надо терпеть это вот всё, лечите себя сами...

У меня простой вопрос. А вы готовы отправить своего сына/дочь во врачи? Низкая зарплата, тяжёлая работа, риск заболеть самому и принести заразу домой, ответственность (в том числе перед прокуратурой) и т.д. Перспектива!

\section{Результаты исследования: позиция врачей}

Несмотря на то, что в 2020 г. количество комментариев в защиту врачей значительно выросло, врачи склонны скептически оценивать волну героизации медицинского персонала, произошедшую на фоне пандемии COVID-19. Сравнивая два аналогичных поста блогера А. Лебедева, я заметила, что в 2019 г. врачи, хоть и в небольшом количестве комментариев, но участвовали в обсуждении проблем российского здравоохранения, в 2020 же они практически не участвовали в дискуссии, и их отношение транслировалось некоторыми комментаторами с позиции родственников врачей.

В 2019 г. комментарии врачей описывали текущее состояние отрасли: низкий уровень оплаты труда, нехватка персонала, неудачная оптимизация, проблемы в ре- 
гионах и службе скорой медицинской помощи, ограничение времени на прием, низкая квалификация медицинских работников, бюрократия и проч.

В медицине все не так. Во многом сказалось выполнение майских указов, в том числе и путем оптимизации. В основном кадров врачей. Ставки просто сократили. Больницы и поликлиники сократили. Медицина стала недоступна, особенно в сельских районах и малых городах. Врачей не хватает. Узких специалистов не хватает даже в областных центрах. Служба скорой и неотложной помощи практически уничтожены. По зарплатам одни приписки. Наверх идут доклады с какими-то мифическими зарплатами.

Я будущий кардиолог, так вот, я должна буду за 15 минут «обслужить» больного. В большинстве случаев это нереально, потому что большинство пациентов с километровыми диагнозами. Результат - невыполнение плана, срезание зарплаты, трата личного времени. По поводу лечения - благо мы дошли до доказательной медицины и пользуемся клиническими рекомендациями, основанными на мета-исследованиях. Но, конечно, много неграмотных врачей, к сожалению.

1. Врачи перегружены писаниной. Они больше вынуждены писать для страховой чем лечить. 2. Из-за такой бюрократии врач, чтоб не попасть на штрафы вынужден больше заботиться об отчётности, чем о лечении. 3. Страховые штрафуют врачей, за «избыточные» с их точки зрения анализы (например, если врач хочет исключить возможные побочки - страховая скажет, что он назначил «лишнее». В общем - надо меньше бюрократии и больше ответственности за результат. Потому как сейчас важнее написать бумажку и сделать все по инструкции, чем вылечить.

Я работаю в медицине, и от лица государства осуществляю контакт с гражданами. На передовой, так сказать. И вот вся эта медицина для этого контакта. И плохо, когда тылы подводят, у которых нет мнения, что цель медицины этот контакт. В итоге ты принимаешь пациента, заботишься о нем. Еще заботишься о том, чтобы журналы были от руки заполнены, чтобы цели коллег не препятствовали выполнению твоих трудовых обязанностей.

Возможно, отсутствие позиции врачей в обсуждении А. Лебедева в 2020 г. связано с высокой нагрузкой и отсутствием свободного времени на общение в интернете, либо, что также является моим предположением, врачи боятся вызвать негативную ответную реакцию на свою позицию. За время пандемии в нашей стране врачи, которые били тревогу по поводу нехватки средств индивидуальной защиты в регионах, становились объектом преследования со стороны чиновников. В СМИ транслировались истории увольнения медицинских работников за отказ работы в красной зоне. Во время пандемии врачей стали опасаться, так как они рассматривались как потенциальный источник заражения и распространения инфекции (см. рис. 3). Доплаты за работу с ковидными пациентами, а впоследствии за вакцинацию, привели к припискам и случаям мошенничества, что также широко транслировалось СМИ.

Рис. 3. Опасения врачей (интернет-источник)

Для того, чтобы проиллюстрировать отношение врачей к смене настроений пациентов на фоне пандемии COVID-19, я анализировала публичные комментарии 
русскоговорящих врачей из разных стран (в том числе из США и РФ) в социальной сети Facebook. Они отмечали, что в условиях пандемии, когда врачи вынуждены были находиться в красной зоне в средствах индивидуальной защиты, медицинский персонал обезличивался, что в контексте человечности сильно отдаляло пациента от врача. Одним из важнейших шагов после завершения пандемии, как представляется, будет налаживание коммуникаций между врачом и пациентом, восстановление эмпатии к больным со стороны медиков, чему сейчас мешает конвеерный характер их работы и большие психологические нагрузки.

Эта вся геройская тема осточертела врачебному сообществу. Оно и так исполняет свой долг, в том числе и бесплатно, но не надо из врача делать Боксера из Скотного двора. В нас все, что нужно, вшито без всяких клятв и присяг. Но вот если мы, например, не захотим оставлять сиротами своих маленьких детей, или вдруг нам не выплатят причитающуюся и обещанную плату за страх (Ж. Арно, на всякий случай), то мы будем уходить, как и все бы ушли, и претензии просим предъявлять к тем, кто сносит больницы, устраивает давки в метро и врет в глаза о благополучии, и уж своих детей точно в ковидные стационары не пошлет, да и самих их впереди на лихих конях что-то не видно. В медицинском сообществе зреет недовольство на грани взрыва. Еще пару свободных профсоюзов, конечно, объявят агентами Госдепа, педофилами, либерастами, кем там еще. Но ведь врачи - это не журналисты, не артисты и не спортсмены. Без врачей, вот незадача, можно и помереть. Так что, если не можете помочь материально, не учите жить и аплодируйте по вечерам с балконов (врач, Москва) ${ }^{1}$.

Немного еще геройской лирики. Когда я писал, что не надо делать из медработников героев, я был совершенно искренен. В начале эпидемии было очень неприятно, страшно и горько. Вокруг было много смертей, отчаянья и обнажившихся проблем. На всех уровнях. Проблемы больницы, города, всего мира, как это ни пафосно звучит. На то и пандемия, что затронут был весь мир. Ничего геройского при этом никто не делал. Больше всего после заболеть и заразить семью, я боялся, что наших ресурсов не хватит. Что те люди, которые пишут на дверях больницы «спасибо нашим героям» пойдут громить больницу. <..> При таком количестве работы/смертей врачи теряют эмпатию, при гипер-потоке пациентов нет возможности уделить каждому время <..> Мне все-таки кажется, что врач немного не равно машинке по выдаче таблеток, небулайзеров и капельниц, а внимательно наблюдать за ходом выздоровления, не мешая ему, вполне оправданная тактика. Ну и что услышать от врача, что в данный момент индивид не нуждается в медикаментозной терапии - совсем не оскорбление, а повод немедленно выпить. Без всякого гепатопротектора (врач, Нью-Йорк)².

Чтобы не оставлять претензии к отечественной медицины без ответа со стороны врачей, я провела экспертное интервью с врачом, начавшим свою практику в начале 1980-ых годов. Я отобрала высказывания пациентов под постами А. Лебедева 2019 и 2020 годов и попросила моего респондента прокомментировать их (ПМА 2021).

Обращение пациентов за разными мнениями к различным врачам мой респон-

\footnotetext{
${ }^{1}$ Сообщество «Мнения о здравоохранении» в социальной сети Facebook. См. подробнее: https:// www.facebook.com/groups/179139158799444/permalink/2935486936497972/.

${ }^{2}$ Страница Евгения Пинелиса в социальной сети Facebook - https://www.facebook.com/evgeny.pinelis.
} 
дент считает порочной практикой:

Желание пациентов получить как можно больше мнений разных докторов губительно. Сам он не может принять решение о выборе того или другого метода и получается замкнутый круг. Есть высказывание английского реаниматолога: - Один врач - хорошо, два - лучше, три - еще лучше, но здоровье пациента убывает с количеством врачей!!

Мнимая медицинская грамотность российских пациентов также вызывает опасения у врачей, категоричные высказывания пациентов о том, как нужно вести себя врачам в той или иной ситуации, как и обвинения в некомпетентности со стороны «знающих» пациентов врачи связывают с падением уровня престижа врачебной профессии и снижением пиетета и уважения к ней.

Отросток отростку рознь. Зачастую это очень сложная операция, которую лапароскопически не решить. Я лично зависал на апендэктомии на 5 часов. Проблема в незнании.

Советы комментаторов больше писать жалобы в вышестоящие инстанции, чтобы добиться «положенного» медицинского обслуживания, также воспринимается врачами негативно.

... Потому что реакция на жалобы стала неадекватной. Никто не разбирается, сразу наказывают врача. От этого и снижается престиж профессии. Раньше на необоснованные жалобы вообще не обращали внимания.

В целом отзывы пациентов о бесполезности государственной бесплатной медицины связаны по мнению врачей с результатами оптимизации и реформирования системы здравоохранения, которая началась в начале 2000 -х годов. Необходимость самоокупаемости и экономии на всем привели к тому, что к некоторым специалистам особенно в регионах невозможно записаться, для получения бесплатной медицинской помощи необходимо собирать множество справок, анализов и направлений, что также затягивает начало лечения, а пациенты вынуждены обращаться в коммерческие медицинские организации или пользоваться платными медицинскими услугами в государственных клиниках.

Это серьезная проблема после оптимизации системы здравоохранения. Как ее будут решать пока не понятно. Но это конкретные ошибки руководства. У каждой ошибки есть имя отчество и фамилия!! В совке - это было невозможно. Дооптимизировались.

Мой респондент, как и многие комментаторы постов А. Лебедева, считает, что для улучшения сложившейся ситуации неудовлетворенности граждан системой здравоохранения, необходимо в первую очередь найти «своего врача», врача, которому пациент будет доверять и консультироваться при возникновении проблем со здоровьем у себя и своих близких. Это должен быть врач, - аналог семейного врача или general practitioner (GP - врач общей практики в Великобритании), знающий семейный анамнез и индивидуальные особенности своих пациентов, готовый подсказать, направить, сориентировать в потоке информации медицинской терминологии, процедур и правил.

Прочитай хоть тысячи источников, самостоятельно принять решение о тактике и 
стратегии лечения не в состоянии ни один человек. Тем более, когда речь идет о здоровье твоем или близкого тебе человека. Для этого и есть доктора. Но только это должны быть ДОКТОРА готовые принять на себя порой крайне трудное решение (возможно фатальное), а не перепихивать это решение на перепуганного и ничего не понимающего человека, который готов поверить во что угодно и кому угодно. На самом деле ВСЕ В ПОИСКАХ ХОРОШЕГО ВРАЧА.

От этого и рост обращений наших граждан в больницы запада, (который, я думаю, сейчас закончится). Они едут за ПАТЕРНАЛИЗМОМ. Они ждут что там за них решат все, остается только заплатить. Платят и с теми же проблемами возвращаются назад. Я всегда говорю, если просят мое мнение - ЛЕЧИТЬСЯ НАДО ТАМ, ГДЕ ЖИВЕШЬ. На самом деле нет неприятия патернализма. Мои пациенты предельно счастливы, выполняя мои решения. По патернализму народ скучает!

Сегодня у нас наевшийся реформ здравоохранения народ. Крайне растерянные врачи. Уходит старое поколение. Система образования, как и все в стране, просело. Отсюда и абсолютные неучи доктора и крайне недовольные ими пациенты. И заметь, если врач хороший, то никаких проблем с пациентами он не имеет, и никто не прикапывается к нему с «гайдлайнами».

Что нужно делать? Надо восстанавливать: систему здравоохранения, систему планирования и кадров, и ресурсов, систему обучения. Надо перестать копировать то, что не копируется. Надо перестать заигрывать с пациентами. Надо создать систему омбудсменов в медицине. Нужно собрать небольшое сообщество очень уважаемых медицинских специалистов, без одобрения которых невозможно будет принять ни одно решение в медицине.

Можно услышать мнение, что российское здравоохранение «громоздкое», «опасное», «отталкивающее», «неудобное», «пугающее», «безликое» и «равнодушное» (Пиетиля и др. 2007), но врачи полагают, что в сложившихся условиях главное - результат лечения.

... Вероятно по мнению пассажиров суперскоростной поезд тоже является опасным, громоздким, неудобным и пугающим, но в данной ситуации главное, чтобы он вас довез до точки назначения. И пассажир не может оценить функциональность мотора, логистические параметры и т.д. Точно так же в медицине, главное - это здоровье населения. Если это здоровье улучшается, снижается смертность, растет продолжительность жизни, снижается инфекционная заболеваемость, то населению абсолютно не важно КАКИМ образом этого добились.

\section{Выводы}

В заключении хочу отметить, что смена настроений российского общества в сторону благодарности и уважения труда медицинского персонала произошла примерно в середине апреля 2020 г., когда повсеместно стали объявляться локдауны, а в СМИ и сети интернет начались массовые акции поддержки врачей. Волна, пришедшая к нам с Запада, сначала была воспринята неоднозначно, но впоследствии возросло количество публикаций и сюжетов на телевидении о поддержке и уважения труда 
врачей. Российские пациенты, оценивая современную медицину, видят и адекватно оценивают весь комплекс проблем: и бюрократические, и организационные, и финансовые. Но, когда в многочисленных обсуждениях в сети интернет затрагиваются их личные переживания и опыт, особенно в вопросах здоровья и риска жизни, страх и эмоции перевешивают логику и рациональность. И хотя актуальные статистические данные от 2021 г. говорят о том, что удовлетворенность россиян медицинской помощью продолжает снижаться (Ремедиум 2021), медицинские антропологи со сдержанным оптимизмом отмечают рост уважения и благодарности к врачам за их колоссальный труд. Остается надеяться, что эта тенденция продолжится и дальше.

Данное исследование является небольшим и в определенной степени ситуативным, так как вероятность появления одного и того же поста блогера-миллионника с разницей в год, вызванного резкой сменой медицинской повестки и объявлением пандемии COVID-19, было бы сложно представить в другое время. Сравнительный анализ отзывов пользователей о проблемах российской медицины, дал робкую надежду на изменение настроений в обществе. В начале 2022 года мы все еще находимся в условиях пандемии, а пациенты продолжают свои дневниковые записи об опыте их пребывания в ковидных госпиталях, о течении заболевания и вариантах лечения, о пост-ковидном синдроме, который еще предстоит изучать, в том числе с участием медицинских антропологов, в режиме реального времени ведущих наблюдения за публичной активностью пациентов и их родственников в сети интернет.

\section{Источники и материалы}

Котов 2020 - Котов М. Эффективная коммуникация с пациентами. Максим Котов, врач-онколог, НМИЦ онкологии // Виртуальная мастерская «Вокруг медицины» Онлайн-мероприятие. - 2020. https://www.facebook.com/events/2560866367496357 (дата обращения: 03.06.2020).

Моисеева 2013 - Моисеева О.Н. Круглый стол «Врач-пациент-общество: модели и реальность» // Медицинская антропология и биоэтика, 2013. № 1 (5). http://www.medanthro. ru/?page_id=1160 (дата обращения: 03.08.2019).

ПМА 2019 - Лебедев А. - анализ онлайн высказываний пациентов о современном состоянии российской медицины и их опыте обращения в медицинские учреждения. Ссылка на публикацию: https://comments.bot/thread/FsptVTsUl (дата обращения: 12.10.2021).

ПМА 2020 - Лебедев А. - анализ онлайн высказываний пациентов о современном состоянии российской медицине и их опыте обращения в медицинские учреждения. Ссылка на публикацию: https://comments.bot/thread/VcqZuPB51 (дата обращения: 12.10.2021).

ПМА 2021 - Александр Андреевич В. - устное интервью с врачом с 40-летним стажем.

Ремедиум 2021 - Группа Ремедиум «Мониторинг жалоб и обращений пациентов в связи с проблемами получения медицинской помощи в системе OMC». https://remedium.ru/news/ udovletvorennost-rossiyan-medp/ (дата обращения: 30.04.2020.)

Харитонова 2020 - Харитонова В.И. Медицинская антропология на пороге третьего десятилетия XXI века // Медицинская антропология и биоэтика, 2020. № 2 (20). http://www. medanthro.ru/?page_id=5295 (дата обращения: 26.05.2021).

Харитонова 2021 - Харитонова В.И. Медицинская антропология перед новыми вызовами // Медицинская антропология и биоэтика, 2021. № 2 (22).

\section{Научная литература}

Вяткина Н.А. Уровень медицинской грамотности российских пациентов в оценке врачей [Электронный ресурс] // Сибирские исторические исследования, 2019. № 4. http:// journals.tsu.ru/siberia/\&journal_page=archive\&id=1928 (дата обращения: 30.04.2020.). DOI: 


\section{$10.17223 / 2312461 X / 26 / 8$.}

Денисов И.Н. Профилактика претензий к качеству медицинского обслуживания. Роль коммуникативных навыков врачебного персонала / И.Н. Денисов, А.Г. Резе, А.В. Волнухин // Проблемы социальной гигиены, здравоохранения и истории медицины, 2012. № 6. С. 32-35.

Иевенко С., Дубас Н. Оптимальная модель медицинского страхования для России // Атлас страхования, 2010. Июнь (№ 6).

Кулакова Е.В., Богомолова Е.С., Назарова Е.В. Медицинская активность родителей, имеющих детей дошкольного возраста // Медицинский альманах «Организация здравоохранения и общественное здоровье», 2011. № 4 (17). С. 18.

Лехииер В.Л. (под общ. ред.) Общество ремиссии на пути к нарративой медицине: сб. науч. тр. Самара: Изд-во «Самарский университет», 2012. 296 с.

Лехциер В.Л. Болезнь: опыт, нарратив, надежда. Очерк социальных и гуманитарных исследований медицины. Вильнюс: Logvinoliteratūrosnamai, 2018. 312 с.

Ожсианова А.А. «Активное недоверие» врачам: случай юридического сопровождения родов // Сибирские исторические исследования, 2020. № 4. DOI: 10.17223/2312461X/30/10.

Пиетиля И., Дворянчикова А.П., Шилова Л.С. Российское здравоохранение: ожидания населения // Социология здоровья и медицины, 2007. С. 1-16.

Присяжнюк Д.И. Трансформация профессии врача в условиях реформы здравоохранения: дисс. ... к. социол. н.. М., 2012. 184 с.

Пузанова Ж.В., Хуртина В.В. Особенности организационного поведения российских врачей // Вестник РУДН, серия Социология, 2014. № 2. С. 146.

Романов П.В., Ярская-Смирнова Е.Р. Профессии социального государства / под ред. П.В. Романова и Е.Р. Ярской-Смирновой (Библиотека «Журнала исследований социальной политики»). М.: ООО «Вариант», ЦСПГИ, 2013. 360 с.

Троцук И.В. Нарратив как междисциплинарный методологический конструкт в современных социальных науках // Вестник РУДН, серия Социология, 2004. № 6-7. С. 56-74.

DiMatteo, M. Robin. Enhancing Patient Adherence to Medical Recommendations // Journal of the American Medical Association, 1994. No. 271 (1). Pp. 79-83.

Gordon, Geoffrey H., Laurence Baker, and Wendy Levinson. Physician-Patient Communication in Managed Care. // Western Journal of Medicine 1995. Vol. 163. Pp. 527-31.

Laine, Christine and Frank Davidoff. Patient-Centered Medicine. A Professional Evolution // Journal of the American Medical Association, 1996. No. 275 (2). Pp. 152-56.

Mead, N., Bower, P. Patient-centeredness: A Conceptual Framework and Review of the Empirical Literature // Social Science and Medicine. 2000. No. 51. Pp. 1087-110.

Stewart, Moira A. Effective Physician-Patient Communication and Health Outcomes: A Review. // Canadian Medical Association Journal. 1995. No.152 (9). Pp. 1423-33.

Stewart, Moira, Judith Belle Brown, W. Wayne Weston, Ian R. McWinney, Carol L. McWilliam, and Thomas R. Freeman. Patient-Centered Medicine. Transforming the Clinical Method, 2nd ed. Oxon, UK: Radcliffe Medical Press Ltd. 2003.

Williams, Susan, John Weinman, and Jeremy Dale. Doctor-patient Communication and Patient Satisfaction: A Review. // Family Practice. 1998. No. 15 (5). Pp. 480-492.

Wynia, Matthew and Jennifer Matiasek Promising Practices for Patient-Centered Communication with Vulnerable Populations: Examples from Eight Hospitals. // New York: The Commonwealth Fund. Retrieved May 8, 2009 (http://www.commonwealthfund.org/publications/publications show.htm?doc_id=3 97067).

\section{References}

Denisov, I.N. 2012. Profilaktika pretenzij k kachestvu medicinskogo obsluzhivaniya. Rol kommunikativny`x navy'kov vrachebnogo personala [Prevention of claims to the quality of medical care. The role of communication skills of medical staff]. Problemy' social noj gigieny', zdravooxraneniya $i$ istorii mediciny ${ }^{6}$ : 32-35.

DiMatteo, M. Robin. 1994. Enhancing Patient Adherence to Medical Recommendations. Journal of the American Medical Association 271 (1): 79-83. 
Gordon, Geoffrey H., Laurence Baker, and Wendy Levinson. 1995. Physician-Patient Communication in Managed Care. Western Journal of Medicine 163: 527-31.

Ievenko S., Dubas N. 2010. Optimal naya model medicinskogo straxovaniya dlya Rossii [The optimal model of medical insurance for Russia]. Atlas straxovaniya. July (№6).

Kulakova E.V., Bogomolova E.S., Nazarova E.V. 2011. Medicinskaya aktivnost` roditelej, imeyushhix detej doshkol nogo vozrasta [Medical activity of parents with preschool children] In Medicinskij al 'manax «Organizaciya zdravooxraneniya i obshhestvennoe zdorov`e». 4 (17): 18.

Laine, Christine and Frank Davidoff 1996. Patient-Centered Medicine. A Professional Evolution. Journal of the American Medical Association 275 (2): 152-156.

Lexcier V. L. 2012. Obshhestvo remissii na puti $k$ narrativoj medicine [Remission Society on the Way to Narrative Medicine]: sbornik nauchnykh trudov, edited by Lexcier V.L. Samara: Izdatel'stvo «Samarskij universitet» $296 \mathrm{p}$.

Lexcier V.L. 2018. Bolezn`: opy't, narrativ, nadezhda. Ocherk social'ny'x $i$ gumanitarny'x issledovanij mediciny ' [Illness: experience, narrative, hope. Essay on social and humanitarian studies of medicine], edited by Lexcier V.L. Vil’nyus: Logvinoliteratūrosnamai, $312 \mathrm{p}$.

Mead, N., Bower, P. 2000. Patient-centeredness: A Conceptual Framework and Review of the Empirical Literature Social Science and Medicine 51: 1087-110.

Ozhiganova A.A. 2020. «Aktivnoe nedoverie» vracham: sluchaj yuridicheskogo soprovozhdeniya rodov ["Active mistrust" of doctors: the case of legal support of childbirth]. Sibirskie istoricheskie issledovaniya. №4. DOI: 10.17223/2312461X/30/10.

Pietilya I., Dvoryanchikova A.P., Shilova L.S. 2007. Rossijskoe zdravooxranenie: ozhidaniya naseleniya [Russian healthcare: expectations of the population] Sociologiya zdorov'ya $i$ mediciny '1: 1-16.

Prisyazhnyuk D.I. 2012. Transformaciya professii vracha v usloviyax reformy zdravooxraneniya [Transformation of the medical profession in the context of healthcare reform]. $\mathrm{PhD}$ diss. Higher School of Economics Moscow.

Puzanova Zh.V., Xurtina V.V. 2014. Osobennosti organizacionnogo povedeniya rossijskix vrachej [Features of organizational behavior of Russian doctors] Vestnik RUDN, seriya Sociologiya. 2: 146.

Romanov P.V., Yarskaya-Smirnova E.R. 2013. Professii social'nogo gosudarstva [Professions of the welfare State] edited by P.V. Romanova and E.R. Yarskoj-Smirnovoj (Biblioteka «Zhurnala issledovanij social`noj politiki»). Moscow: OOO «Variant».

Stewart, Moira A. 1995. Effective Physician-Patient Communication and Health Outcomes: A Review. Canadian Medical Association Journal 152(9): 1423-1433.

Stewart, Moira, Judith Belle Brown, W. Wayne Weston, Ian R. McWinney, Carol L. McWilliam, and Thomas R. Freeman. 2003. Patient-Centered Medicine. Transforming the Clinical Method, 2nd ed. Oxon, UK: Radcliffe Medical Press Ltd.

Troczuk I.V. 2004. Narrativ kak mezhdisciplinarny`j metodologicheskij konstrukt v sovremenny`x social `ny`x naukax [Narrative as an interdisciplinary methodological construct in modern Social sciences]. Vestnik RUDN, seriya Sociologiya 6-7: 56-74.

Vyatkina N.A. 2019. Uroven` medicinskoj gramotnosti rossijskix pacientov v ocenke vrachej [Health literacy among patients in Russia as assessed by Russian physicians] In Sibirskie istoricheskie issledovaniya. 4: 162-180. DOI: 10.17223/2312461X/26/8.

Williams, Susan, John Weinman, and Jeremy Dale. 1998. Doctor-patient Communication and Patient Satisfaction: A Review. Family Practice 15 (5): 480-492.

Wynia, Matthew and Jennifer Matiasek. 2009. Promising Practices for Patient-Centered Communication with Vulnerable Populations: Examples from Eight Hospitals. New York: The Commonwealth Fund. Retrieved May 8, 2009 (http://www.commonwealthfund.org/publications/publications_show. htm?doc_id=3 97067). 